\title{
Analysis of Partially Evacuated Solar Still System under Jordan Climate
}

\author{
Ahmed Qandil', Ibrahim Abu Alshaikh², Nader Aljabarin ${ }^{3 *}$, \\ Khalid S. Rababa ${ }^{4}$, Nabil Beithou ${ }^{4}$ \\ 1 Civil Engineering Department, Applied Science University Private, Amman, Jordan \\ 2 Mechanical Engineering Department, Jordan University, Amman, Jordan \\ 3 Natural Resources and Chemical Engineering Department, Tafila Technical University, Tafila, Jordan \\ 4 Mechanical Engineering Department, Tafila Technical University, Tafila, Jordan \\ * Corresponding author's e-mail: aljabarin@yahoo.com
}

\begin{abstract}
The pressing need for reducing the global warming effects from the emission of greenhouse gases necessitates the use of renewable energy where possible. Solar distillers are devices with a promising future. In this work, an experimental setup (solar distiller) was constructed and equipped with a mirror, basin, glass cover, compressor, sensors and controllers to study the partial evacuation effects on different solar distillation parameters and the production capacity under the Jordanian climate. The test rig was tested for three different water levels $(1,2$ and $3 \mathrm{~cm})$, and four pressure values $(1,0.9,0.8$ and $0.7 \mathrm{~atm})$ under the Jordanian climate. The detailed experimental results strongly correlate with the results previously published in literature. The modifications performed on the system doubled the previously attained efficiency. These improvements in the solar distiller will favor the application of the vacuum pressure principle in many different applications, such as the water extraction from the atmospheric air.
\end{abstract}

Keywords: solar energy, distillation development, Jordan climate, partial vacuum pressure.

\section{INTRODUCTION}

The energy cost and scarcity lead to imposing the use of renewable energy in different applications. Solar distillers are used in water treatment to produce high purity water; however, the used equipment is obsolete and originated before the scientists started dealing with solar radiation measurement. Solar distillation has wide practical applications in sea water treatment, brackish water treatment and industries [Tiwari et al 2003]. As fresh water constitutes less than $2.6 \%$ of the water available on the Earth, scientists focused on improving and devising different distillation techniques. Manchanda and Kumar [2017], studied the water desalination techniques, they presented a review on the active solar distillation methods [Manchanda 2017]. Naim and Abd El Kawi [2003] constructed a Solar Still (SS) with charcoal. Charcoal functions as a heat absorber and as a wick; the application of this solar still resulted in a $15 \%$ increment in productivity over wick-type stills. The authors added that such a SS has many advantages, including low thermal capacity, light weight and simple operation. Muslih et al. [2010] compared the added cost on different types of the water distillation equipment to the amount of the collected distilled water. The study considered a traditional single slope SS, a reflecting insulated mirrors SS, a stepped basin $\mathrm{SS}$, and a single axis sun tracking system. They found that the system with the stepped basin is most feasible, followed by the sun tracking with stepped basin, and then the reflecting mirror system. The payback periods of such modifications ranged from 2.1 to 4.6 years.

As a result of the continuous science development, the SS systems achieved extra potential 
with nanofluids. Nanofluids are fluids with nano particles that may have high potential in heat transfer fluids. They could enhance the thermophysical properties of fluids and improve the heat transfer performance of the system. Saidur et al. [2011] performed a review on the applications and challenges of nanofluids. They reported the wide applications of nanofluids such as that in cooling engines, heat exchangers and electronics, also nanofluids increases the efficiency of diesel generators, chillers and refrigerators. The application of nanofluids is extended even in Nuclear reactors and space industries in addition to defense and solar water heating. It has been concluded from the review that nanofluids have a strong temperature-dependent thermal conductivity at very low particle concentrations than conventional fluids, which may improve the performance of many systems. Velmurugan and Srithar [2011] conducted a review on the performance of SS and the various parameters affecting its productivity. They considered various research works don, authors found that water surface free area, absorber area, temperature difference between water surface and glass, water inlet temperature, depth of water layer and glass angle are the main parameters affecting the productivity of a SS system. Velmurugan and Srithar review was valuable even they did not mention some important parameters such as the basin internal pressure and the heat losses form the SS system [Omar et al. 2013]. Chung et al. [2012] designed a low pressure-temperature evaporation system for converting brackish water into fresh water by distillation. The designed system implements the ejector as a vacuum creator thus liquid can evaporate at a relatively lower temperature than that at atmospheric pressure. Furthermore they analyzed the effect of feed water temperature and orifice diameter on the performance of the distillation system. The authors concluded that condensate vapor increased with flow rate and temperature. It also decreased if the orifice diameter is enlarged. Vacuumed SS with nanofluid performance is further analyzed by [Kabeel et al. 2014]. Gnanadason et al. fabricated a single basin vacuum SS, and tested it with nanofluids and without. They reported that the innovated low pressure SS enhances the water distillation compared to the conventional SS system.

Scientists focused more on nanofluids, they performed many studies regarding the convective heat transfer and friction factor, that affect the nanofluids turbulent flow as in [Heyhat 2012]. The results reveal that the heat transfer coefficient for nanofluid is improved with increasing the particle concentration, whereas the Reynolds number did not show a valuable enhancement on heat transfer. To predict the convective heat transfer and viscous pressure drop the thermal conductivity and viscosity of the nanofluids should be used. More modifications were imposed to improve the performance of SS system, such as Phase change material and composite materials as in [Hemin 2015], the increment in distilled water production was clarified for both PCM and combination of PCM with composite materials.

Prakash and Velmurugan [2015] reviewed the parameters influencing SS productivity. Velmurugan and Srithar [2011] tested heat storage and phase change materials, whereas vacuum technology was tested by [Prakash 2015]. All reported that vacuum, PCM and heat storage material increase the productivity of the SS, and added that PCM and heat storage materials made distillation even after the solar radiation has been finished. Sharshir et al. [2016] conducted a detailed review of SS systems with the recent developments. Water purification methods and economic analysis have been presented [Manchanda 2017]. Sharshir attempted to enhance the SS performance by using new type of micro-flakes with different weight concentrations, film cooling and different water depths.

The literature shows that the SS systems have a wide range of applications in water purification and industry. As Jordan has a good solar intensity (Figure 1) the applications of such systems are desirable. Many developments have been made enhancing solar desalination systems; these enhancements encourage the use of solar desalination in further applications. In this work a modified SS system has been constructed and tested under the Jordanian climate, for this purpose an experimental setup was constructed and equipped with reflecting mirror, changeable basin, inclined glass cover, evacuation compressor, with suitable sensors and controllers to study the partially evacuation effects on different solar distillation parameters and production capacity.

\section{EXPERIMENTAL SETUP}

To study the performance of SS system under different parameters, a solar distiller was constructed as shown in Figure 2. 


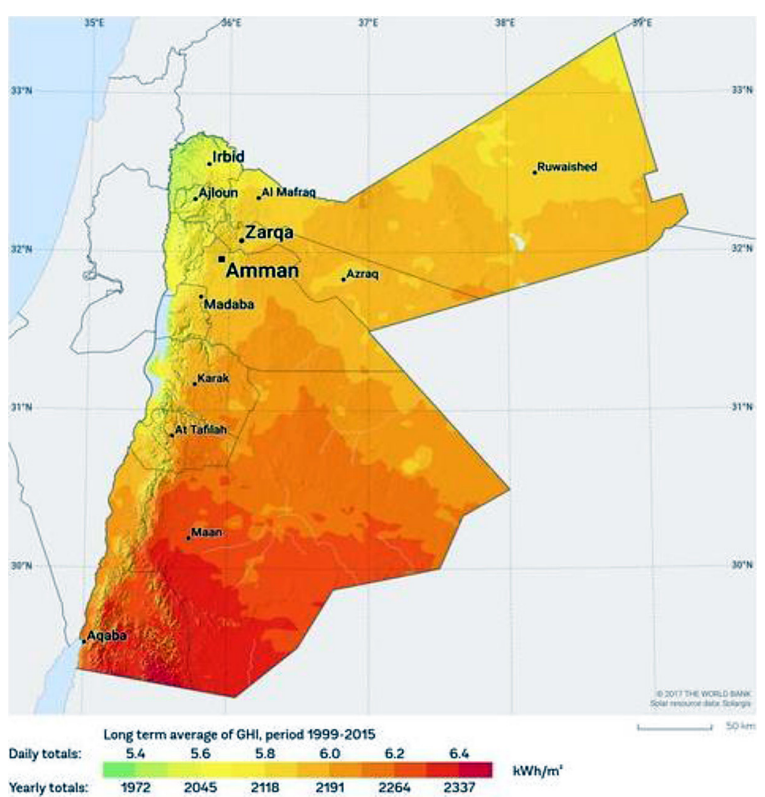

Figure 1. Solar potential distribution in Jordan

The constructed SS system consists of:

- Compressor: creates partial vacuum inside the SS, it assists in water evaporation at lower temperatures. The required pressure in the SS is controlled and adjusted by using pressure sensors.

- High Pressure Control (HPC): electrical solenoid valve, it opens when compressor starts working as pressure is reached to the specified value.

- Low Pressure Control (LPC): electrical solenoid valve, it closes when pressure is reached to the specified value.

- Fresh water collecting tank and withdraw valve: used to withdraw the FW from the tank when it reaches the specified level.

- Pressure Gange: measures the pressure inside the SS.

- Vacuum sensor: an extra sensor used to feel the vacuum pressure required to stop compressor.

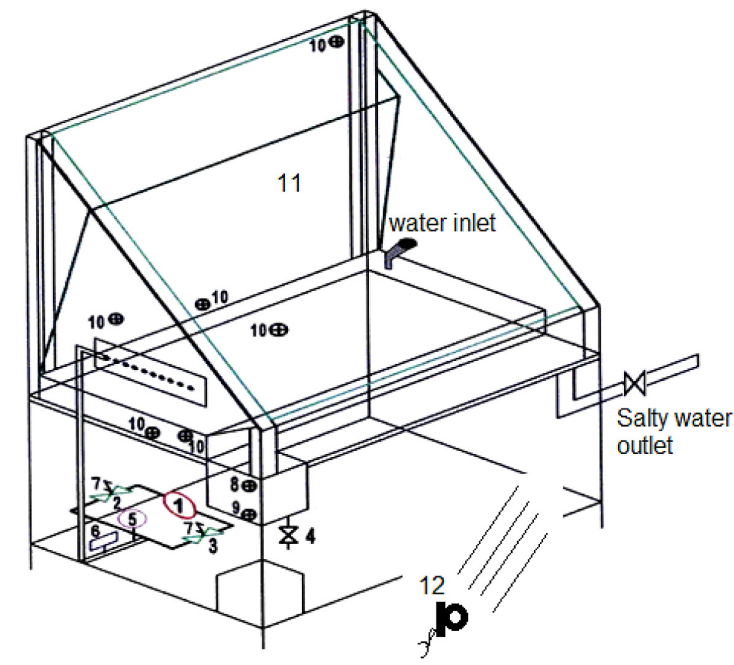

Figure 2. Schematic diagram of the solar still system

- Control Valves: to control the flow of air to and from the system.

- Level sensor FW tank (upper): gives signal when fresh water tank is full, it opens withdrawal valve.

- Level sensor FW tank (lower): indicates that water reached to the bottom of the tank and stop water withdrawal process.

- Temperature sensors: to measure the temperatures of the SS system at various location and time.

- Inclined mirror: reflects the fallen radiation onto the water surface to enhance evaporation.

- Pyranometer: to measure the solar intensity throughout experimentation.

Different views of the actually constructed system are shown in Figure 3. The compressor sensors, controllers, valves, FW tank and mirror are clearly shown. Schematic diagram of the system with dimensions and angles used are illustrated in Figure 4. The system dimensions, materials and controlling parameters are listed in Table 1.
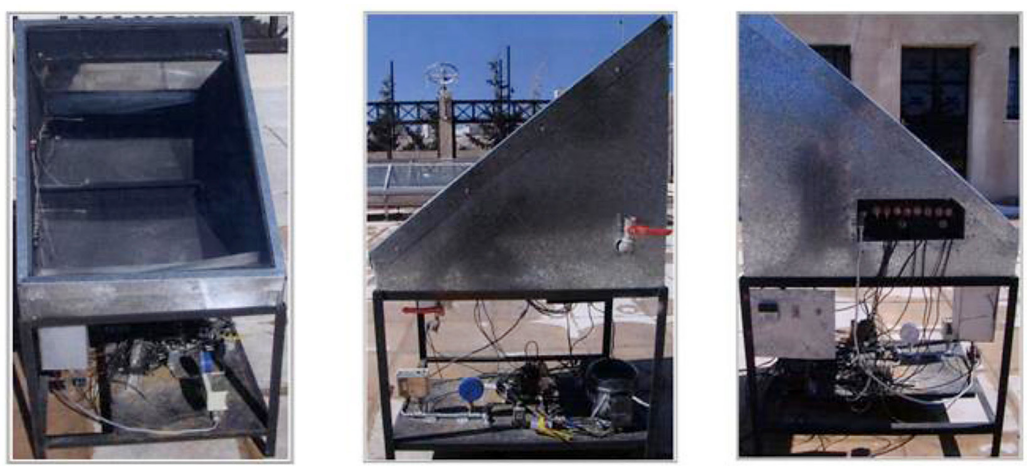

Figure 3. Different views of the constructed setup with the actual system details 
Schematic diagram of the controlling processes of the system relays and contactor is clarified by Figure 5.

Used relays and contactors:

1. $\left(\mathrm{Fs}_{1}\right)$ is lower sensor level fresh water tank.

2. $\left(\mathrm{Fs}_{2}\right)$ is upper sensor level fresh water tank.

3. $\left(\mathrm{C}_{1}\right)$ is a contactor of the low pressure electrical solenoid valve.

4. $\left(\mathrm{C}_{2}\right)$ is a contactor of the compressor

5. $\left(\mathrm{C}_{3}\right)$ is a contactor of the electrical solenoid valve.

6. $\left(\mathrm{C}_{4}\right)$ is a contactor of the high pressure electrical solenoid valve.

7. (VS) is a vacuum sensor.

8. $\left(R_{1}\right)$ is relay of the contactors.

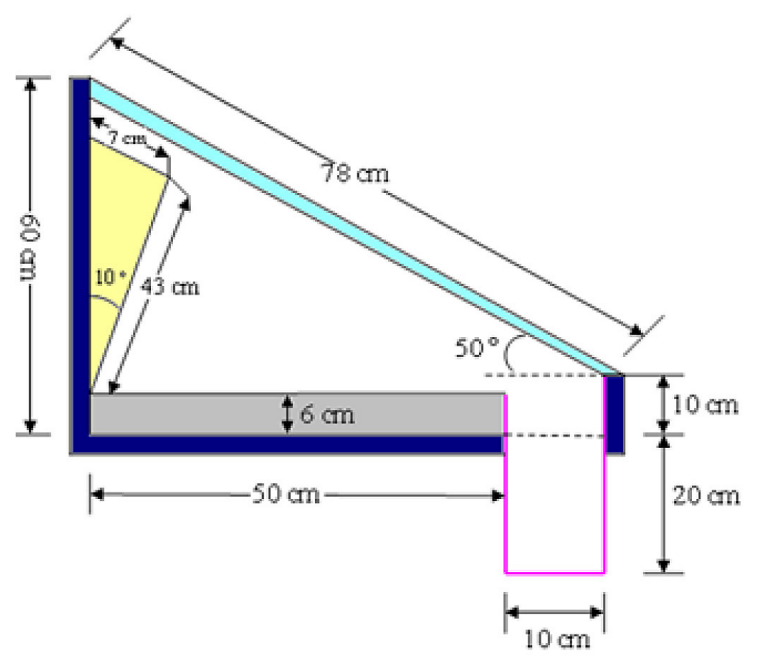

Figure 4. Schematic diagram including dimensions and angles of the SS system

\section{Controlling process}

Branch (1) and branch (5): The sensor (Fs2) is normally open, when the level of water in fresh water tank comes to (Fs2); (Fs2) will be close and relay contactor (R1) will be open and the contactors (C3) and (C4) will be on. Branch (2): The sensor (Fs1) is normally close, when the level of water in fresh water tank comes to (Fs1); (Fs1) will be open and the relay contactor (R1) will be close and the contactor (C3) will be off. Branch (3) and branch (4): The sensor (Fs1) is normally open, when the level of fresh water tank comes to (Fs1); (Fs1) will be close and the contactor (C2) and (C2) will be on and the sensor (VS) 0.7 bar, when the pressure increasing sensor (VS) from 0.7 bar, the sensor will be on and the contactors (C1) and (C2) will be on.

\section{Working principle}

The brackish water enters the SS basin with a pre-calculated amount, this amount determines the water layer thickness. The system pressure is then fixed using the pressure vacuum sensor. When the system is on, the compressor start reducing the pressure inside the SS system until it reaches the required pressure, where vacuum sensor gives sign to the compressor to stop evacuation process. Solar radiation is measured by the Pyranometer. As water evaporates and collected after condensation in the FW tank the various temperatures of the mirror, glass outer and inner temperatures, system, water upper surface and water lower surface temperatures are recorded.

Table 1. System dimensions, materials and controlling parameters

\begin{tabular}{|c|c|c|}
\hline \multirow{2}{*}{ Steel sheets } & Inside & $1.5 \mathrm{~mm}$ \\
\hline & Outside & $1 \mathrm{~mm}$ \\
\hline \multirow{3}{*}{ Glass } & Thickness & $4 \mathrm{~mm}$ \\
\hline & Length & $780 \mathrm{~mm}$ \\
\hline & Width & $500 \mathrm{~mm}$ \\
\hline \multirow{2}{*}{ Mirror angle } & Mirror angle & $10^{\circ}$ \\
\hline & Area & $430 \times 450 \mathrm{~mm}$ \\
\hline Basin water tank & \multicolumn{2}{|c|}{$500 \times 500 \times 60 \mathrm{~mm}$} \\
\hline Fresh water tank & \multicolumn{2}{|c|}{$100 \times 100 \times 200 \mathrm{~mm}$} \\
\hline Compressor Max Power & \multicolumn{2}{|c|}{$120 \mathrm{~W}$} \\
\hline Insulation Thermal Resistance (Rock Wool $25 \mathrm{~mm}$ ) & \multicolumn{2}{|c|}{$0.79 \mathrm{~m}^{2} .{ }^{\circ} \mathrm{C} / \mathrm{W}$} \\
\hline Water layer thickness & \multicolumn{2}{|c|}{1,2 and $3 \mathrm{~cm}$} \\
\hline System Pressures & \multicolumn{2}{|c|}{$101,91,81$ and $71 \mathrm{kPa}$} \\
\hline
\end{tabular}




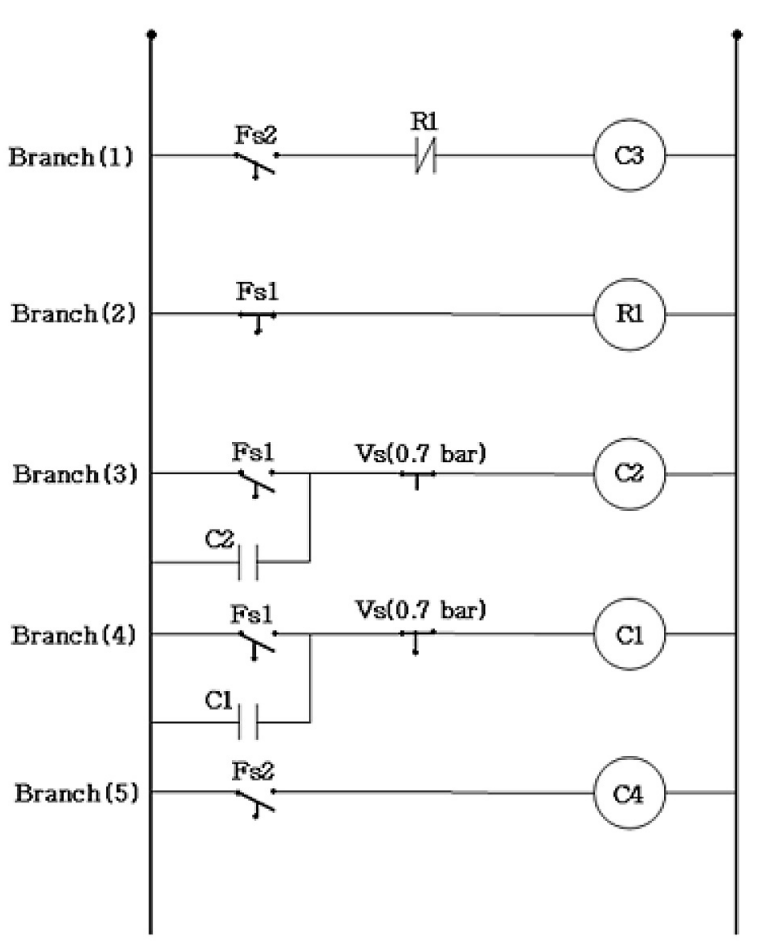

Figure 5. Schematic diagram of the controlling processes of the system

Whenever the system pressure increases over the assigned value, the compressor starts working to bring pressure to the set point again. This process is repeated during the experiment for a various water levels and vacuum pressures.

\section{EXPERIMENTAL RESULTS}

The experiments in this study have been performed 1,2 and $3 \mathrm{~cm}$ ), and different system vacuum pressures $(0,10,20$ and $30 \mathrm{kPa})$ under the Jordanian climatic conditions. The solar radiation, mirror temperature, glass inside and outside temperatures, water layer top and bottom surface temperatures, System Temperature (ST) and accumulated desalinated water are recorded for the different set parameters and time.

A sample data collection is given in Table 2 for the following conditions,

- Solar still (East) with (-10 $\mathrm{kPa})$ vacuum pressure.

- The height of water $3 \mathrm{~cm}$.

- The volume of water 7.5 litter.

The solar radiation, $\mathrm{ST}$, water surface and water bottom temperatures are plotted versus time in Figure 6. As noted from Figure 6, the ST is higher than the water temperatures due to direct heating from solar radiation; the lower temperature of water is due to the heat losses from the device, which indicates that more insulation needed be used for such devices. Radiation increases until it reaches a maximum at solar noon time then start decreasing, as expected. This behavior of the radiation curve affects both the system and water layer temperatures.

The variation of ST and the amount of distilled water versus time are shown in Figure 7 for system pressure $101 \mathrm{kPa}$ (zero vacuum pressure). Figure 7 shows that the Distilled Water Quantity (DWQ) per hour increases rapidly in the morning hours and reaches its maximum at noon time, this value almost constant then after. Figure 8 shows the results of DWQ and various SS temperatures versus time for $10 \mathrm{kPa}$ vacuum pressure and various water thicknesses $(1,2$ and $3 \mathrm{~cm})$. The $\mathrm{ST}$ and DWQ increase with solar intensity as expected, a valuable increase in the STs and DWQs as a result of pressure reduction is notified. Figure 9 and Figure 10 show the variation of STs and DWQs for -20 and $-30 \mathrm{kPa}$, the same trend continues and higher amounts of DWQs are achieved.

Table 2. Sample Data for $3 \mathrm{~cm}$ water layer thickness and $10 \mathrm{kPa}$ system vacuum pressure

\begin{tabular}{|c|c|c|c|c|c|c|c|c|}
\hline Time & $\begin{array}{c}\text { Radiation } \\
\left(\mathrm{W} / \mathrm{m}^{2}\right)\end{array}$ & $\begin{array}{c}\text { Mirror temp. } \\
\mathrm{T}_{1}\left({ }^{\circ} \mathrm{C}\right)\end{array}$ & $\begin{array}{c}\text { Inner glass } \\
\text { temp. } \\
\mathrm{T}_{2}\left({ }^{\circ} \mathrm{C}\right)\end{array}$ & $\begin{array}{c}\text { Outer } \\
\text { glass temp. } \\
\mathrm{T}_{6}\left({ }^{\circ} \mathrm{C}\right)\end{array}$ & $\begin{array}{c}\text { Inner } \\
\text { system } \\
\text { temp. } \\
\mathrm{T}_{3}\left({ }^{\circ} \mathrm{C}\right)\end{array}$ & $\begin{array}{c}\text { Top surface } \\
\text { water temp. } \\
\mathrm{T}_{4}\left({ }^{\circ} \mathrm{C}\right)\end{array}$ & $\begin{array}{c}\text { Bottom } \\
\text { surface } \\
\text { water temp. } \\
\mathrm{T}_{5}\left({ }^{\circ} \mathrm{C}\right)\end{array}$ & $\begin{array}{c}\text { Distillate } \\
\text { output pure } \\
\text { water } \\
\left(\mathrm{kg} / \mathrm{m}^{2}\right)\end{array}$ \\
\hline $9: 00$ & 428 & 21 & 23 & 21 & 26 & 18 & 18 & 0 \\
\hline $10: 00$ & 455 & 33 & 35 & 24 & 38 & 27 & 25 & 0.390 \\
\hline $11: 00$ & 550 & 38 & 39 & 29 & 39 & 32 & 29 & 0.372 \\
\hline $12: 00$ & 647 & 41 & 48 & 32 & 43 & 38 & 30 & 0.263 \\
\hline $13: 00$ & 556 & 37 & 45 & 26 & 41 & 36 & 25 & 0.256 \\
\hline $14: 00$ & 517 & 33 & 41 & 28 & 42 & 33 & 22 & 0.213 \\
\hline $15: 00$ & 500 & 29 & 40 & 27 & 43 & 34 & 21 & 0.197 \\
\hline $16: 00$ & 469 & 25 & 36 & 24 & 44 & 31 & 19 & 0.179 \\
\hline $17: 00$ & 250 & 19 & 31 & 23 & 44 & 29 & 17 & 0.166 \\
\hline
\end{tabular}




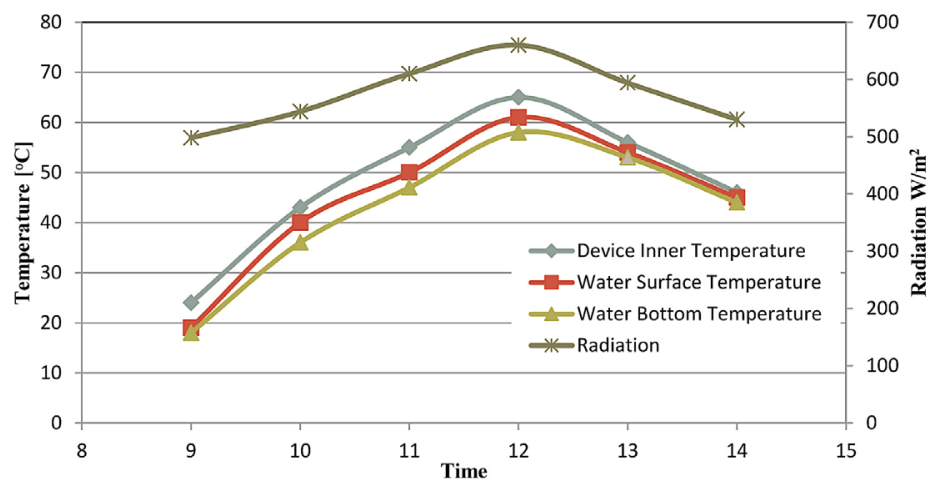

Figure 6. Variation of solar radiation, ST, water surface and water bottom temperatures versus time

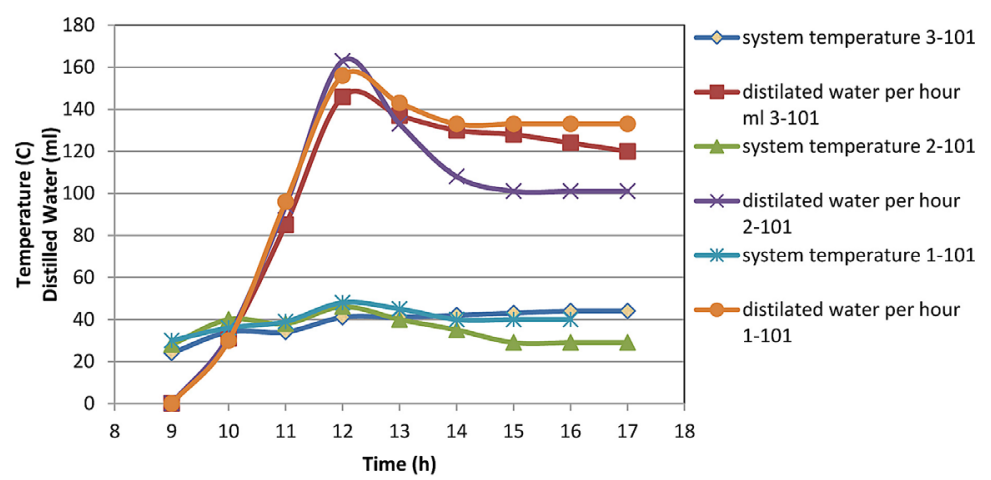

Figure 7. The ST and distilled water quantity versus time for atmospheric pressure and various water thicknesses $(1,2$ and $3 \mathrm{~cm})$

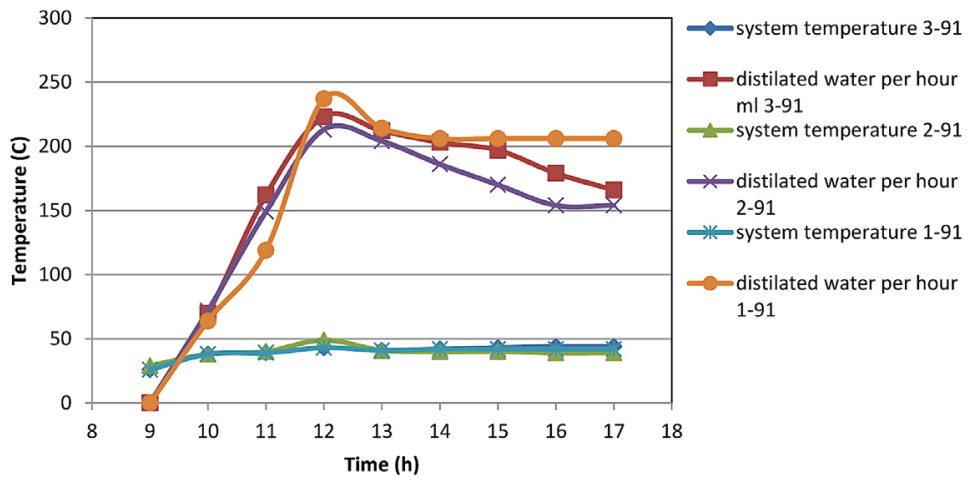

Figure 8. The ST and distilled water quantity versus time for $10 \mathrm{kPa}$ vacuum pressure and various water thicknesses (1,2 and $3 \mathrm{~cm})$

The DWQs $(\mathrm{ml})$ versus Pressure $(\mathrm{kPa})$ are presented in Figure 11 for water thicknesses $(1 \mathrm{~cm}, 2 \mathrm{~cm}$ and $3 \mathrm{~cm})$. It is clear from the Figure that the amount of DWQ increases by increasing the vacuum pressure in the system, this enhancement is applicable for the different water thicknesses. Even though the larger amount of water in the SS requires more time to be heated at the beginning of the experiment, the evaporation quantities do not show significant difference. This is due to the variation in solar energy and extra heat losses accompanied with different water heat transfer areas.

The expected distilled water quantity may be calculated as,

$$
Q=\eta \frac{G A}{2.3}
$$

where $Q$ is the daily quantity of distilled water in $(\mathrm{kg})$,

$G$ is daily global solar irradiation in MJ, $A$ the distiller catchment area $\mathrm{m}^{2}$. For atmospheric pressure and under the achieved 


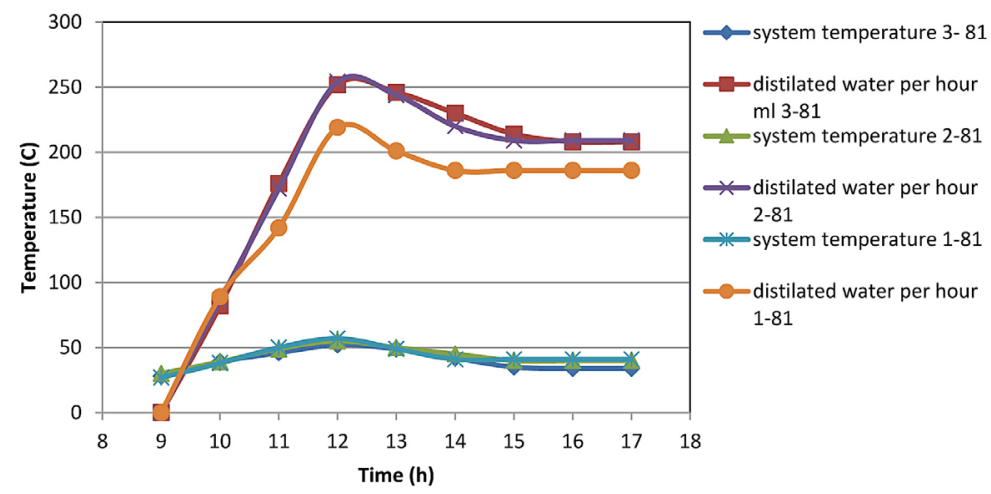

Figure 9. The ST and distilled water quantity versus time for $20 \mathrm{kPa}$ vacuum pressure and various water thicknesses $(1,2$ and $3 \mathrm{~cm})$

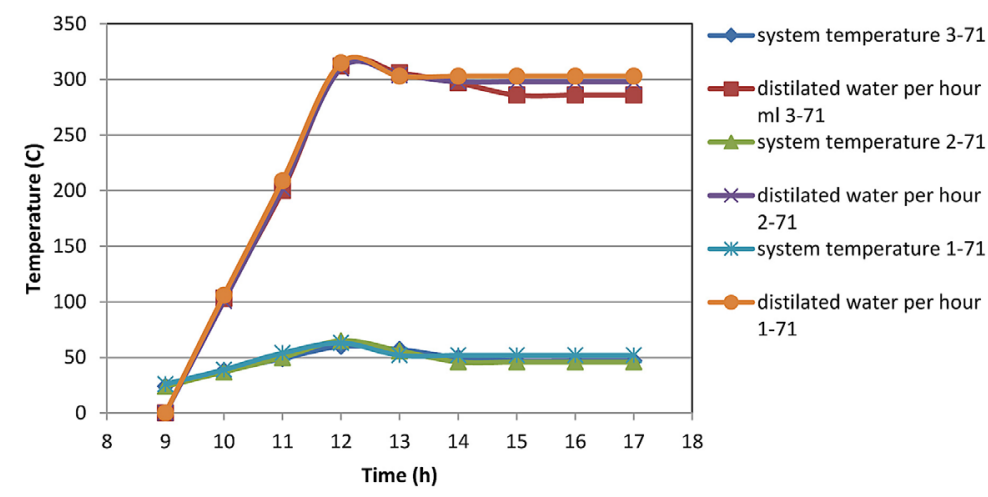

Figure 10. The ST and distilled water quantity versus time for $30 \mathrm{kPa}$ vacuum pressure and various water thicknesses $(1,2$ and $3 \mathrm{~cm})$

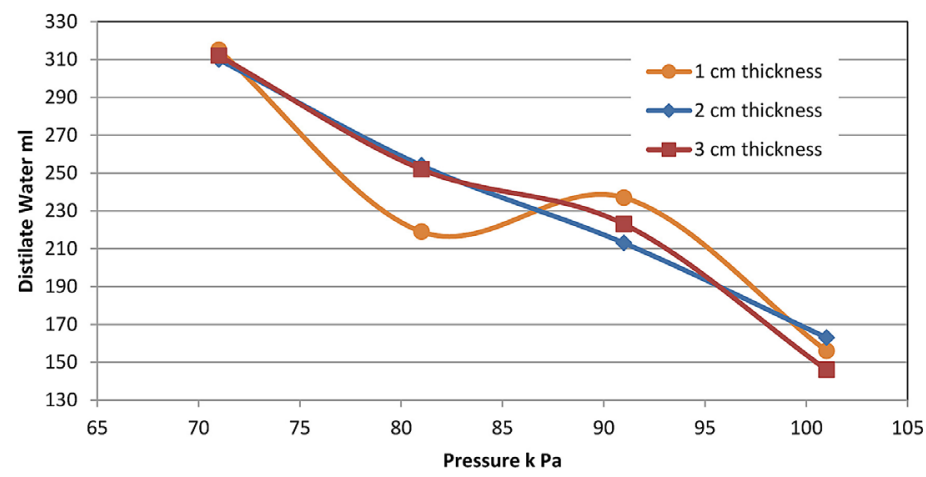

Figure 11. The DWQ and versus Pressure for various water thicknesses $(1 \mathrm{~cm}, 2 \mathrm{~cm}$ and $3 \mathrm{~cm})$

solar radiation, an amount of $41 /$ day is the maximum expected value as shown in the below Figure. A 2.5 1/day were achieved with $30 \mathrm{kPa}$ vacuum pressure.

To visualize more the effect of water thickness on the distillated quantity, the distillated water has been calculated for a fixed time period and compared for different vacuum pressures and water thicknesses, the results are shown in Figure 12. As shown in the pre-mentioned Figure the effect of water thickness for the various vacuum pressures is best at $2 \mathrm{~cm}$ thickness. Even the variation is not high but it is steady in most of the readings, this show that the best water thickness under the selected design and working conditions is $2 \mathrm{~cm}$ thickness.

The efficiency of the SS includes the reflectivity of the glass covers and the heat losses from the SS basin in addition to distiller surface area. Better insulation and high transmissivity glass covers will increase the efficiency of the distiller. 
To calculate the efficiency of the solar distillation system water, the heat required for water evaporation with the incident solar radiation were used. The SS system efficiency may be calculated as,

$$
\eta=\frac{\sum \dot{m}_{d} h_{f g}}{\sum A I}
$$

where: $\dot{m}_{d}$ is the daily water distilled $\mathrm{kg} / \mathrm{day}$

$\mathrm{h}_{\mathrm{fg}}$ is the latent heat of vaporization at the used pressure $\mathrm{J} / \mathrm{kg}$,

I averaged solar intensity $\mathrm{W} / \mathrm{m}^{2}$.

The efficiency of the SS has been calculated and plotted in Figure 13. The solar distiller average efficiency rise about $30 \%$ as reported by Santos et. al. [2017]. This value agrees to a high accuracy with the value achieved in our analyses for the atmospheric pressure case. Figure 13 indicates the achieved high efficiencies of the SS device under vacuum pressure, the efficiency almost double its value for $30 \mathrm{kPa}$ vacuum pressure. The attained results encourage the application of such systems in the different engineering applications. Such system may be used to increase the amount of water that may be achieved from atmospheric air, and makes such device attractive especially in the water scarcity areas.

\section{CONCLUSION}

In order to enhance water evaporation in solar distillers, a partially evacuated solar still was constructed and equipped with suitable sensors and controllers. The effect of pressure evacuation on water distilled capacity was studied under the Jordanian climate. Jordan is characterized by high solar intensity year around; thus the applications of such systems are valuable. The test rig was tested for three different water levels (1, 2 and $3 \mathrm{~cm}$ ), and four pressures (1, 0.9, 0.8 and $0.7 \mathrm{~atm})$.

The experimental results for system temperatures, distilled water quantity and system efficiency were plotted and discussed. The reported efficiency agrees with previously published results in literature. The implemented modifications on the system were able to double the previously attained efficiency. These improvements in Solar distiller capacity will favorite the use of vacuum pressure principle in many different applications. The use of such principle in water extraction from atmospheric air is one of these applications.

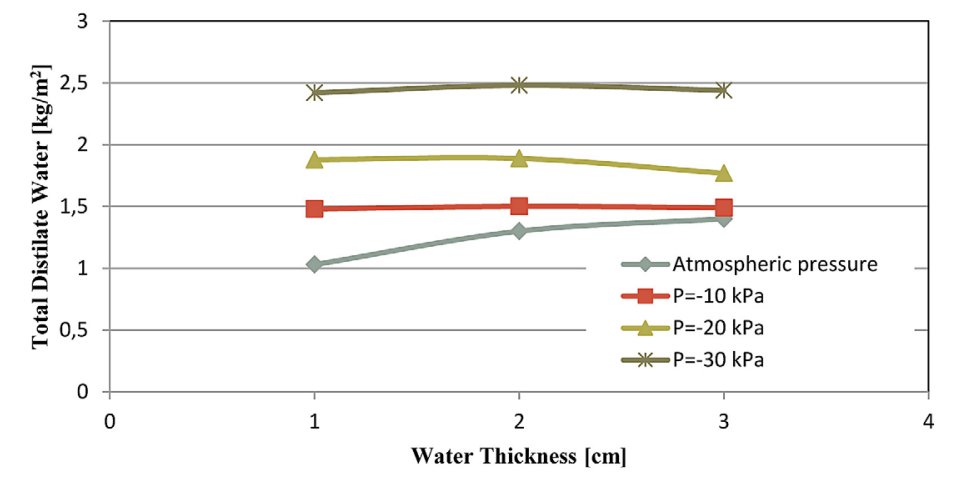

Figure 12. The DWQ $\left(\mathrm{kg} / \mathrm{m}^{2}\right)$ in a fixed time period (6 hours) versus water thicknesses for pressures $(1,0.9,0.8$, and $0.7 \mathrm{~atm})$

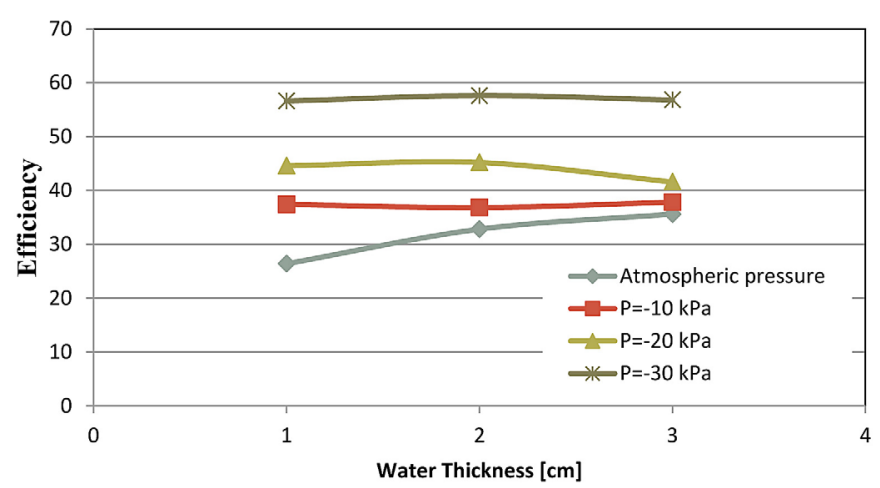

Figure 13. The Solar Still efficiency versus water thicknesses for pressures (1, 0.9, 0.8, and $0.7 \mathrm{~atm})$ 


\section{REFERENCES}

1. Al-Hussaini, H., Smith, I. K. 1994. Enhancing of solar still productivity using vacuum technology. Renewable Energy, 5(1-4), 532-536. doi:10.1016/ 0960-1481(94)90430-8.

2. Al-Hussaini, H. Smith. I. K 1996. Enhancing of solar still productivity using vacuum technology. Fuel and Energy Abstracts, 37(1), 34. doi:10.1016/0140 6701(96)86723-3.

3. Chung, H., Wibowo, S., Fajar, B., Shin, Y., Jeong, H. 2012. Study on low pressure evaporation of fresh water generation system model. Journal of Mechanical Science and Technology, 26(2), 421-426. doi:10.1007/s12206-011-1102-8.

4. Gnanadason M. K., Kumar P. S., Jemilda G., Jasper S.S., 2012, Effect of nanofluids in a modified vacuum single basin solar still, International Journal of Scientific \& Engineering Research Volume 3 , Issue 1.

5. Heyhat, M. M., Kowsary, F., Rashidi, A. M., Alem Varzane Esfehani, S., Amrollahi, A. 2012. Experimental investigation of turbulent flow and convective heat transfer characteristics of alumina water nanofluids in fully developed flow regime. International Communications in Heat and Mass Transfer, 39(8), 1272-1278. doi:10.1016/j. icheatmasstransfer.2012.06.024.

6. Hemin Thakkar, Hitesh Panchal, 2015, Performance investigation on solar still with pcm and nanocomposites: experimental investigation, 2nd International Conference on Multidisciplinary Research and Practice, pp. 334-339.

7. Kabeel, A. E., Omara, Z. M., Essa, F. A. 2014. Improving the performance of solar still by using nanofluids and providing vacuum. Energy Conversion and Management, 86, 268-274. doi:10.1016/j. enconman.2014.05.050.

8. Manchanda, H., Kumar, M. 2017. Study of water desalination techniques and a review on active solar distillation methods. Environmental Progress \& Sustainable Energy, 37(1), 444-464. doi:10.1002/ ep. 12657 .
9. Muslih, I. M., Abdallah, S. M., Husain, W. A. 2010. Cost comparative study for new water distillation techniques by solar energy using. Applied Solar Energy, 46(1), 8-12. doi:10.3103/ s0003701x10010032.

10. Nafey, A., Abdelkader, M., Abdelmotalip, A., Mabrouk, A. . 2001. Solar still productivity enhancement. Energy Conversion and Management, 42(11), 1401-1408. doi:10.1016/s0196-8904(00)00107-2.

11. Naim, M. M., Abd El Kawi, M. A. 2003. Nonconventional solar stills Part 1. Non-conventional solar stills with charcoal particles as absorber medium. Desalination, 153(1-3), 55-64. doi:10.1016/ s0011-9164(02)01093-7.

12. Omar B., Beithou N., Alawin A., Awad A., Abdelhadi Y. Al-Mofleh A., 2013, Experimental study of a vacuumed solar still system, International Journal of Applied Power Engineering (IJAPE), Vol. 2, No. 3, December 2013, pp. 96-104.

13. Prakash, P., Velmurugan, V. 2015. Parameters influencing the productivity of solar stills - A review. Renewable and Sustainable Energy Reviews, 49, 585-609. doi:10.1016/j.rser.2015.04.136.

14. Saidur, R., Leong, K. Y., Mohammad, H. A. 2011. A review on applications and challenges of nanofluids. Renewable and Sustainable Energy Reviews, 15(3), 1646-1668. doi:10.1016/j.rser.2010.11.035.

15. Santos, A., Hernández, E., Ramírez, Z., 2017, Experimental Evaluation of a Single Slope Solar Still, TECCIENCIA, Vol. 12 No. 22, 63-71, 2017 DOI: http://dx.doi.org/10.18180/tecciencia.2017.22.7.

16. Sharshir, S. W., Yang, N., Peng, G., Kabeel, A. E. 2016. Factors affecting solar stills productivity and improvement techniques: A detailed review. Applied Thermal Engineering, 100, 267-284. doi:10.1016/j. applthermaleng.2015.11.041.

17. Tiwari, G. N., Singh, H. N., Tripathi, R. 2003. Present status of solar distillation. Solar Energy, 75(5), 367-373. doi:10.1016/j.solener.2003.07.005.

18. Velmurugan, V., Srithar, K. 2011. Performance analysis of solar stills based on various factors affecting the productivity: A review. Renewable and Sustainable Energy Reviews, 15(2), 1294-1304. doi:10.1016/j.rser.2010.10.012. 